\title{
General public's knowledge and practices on face mask use during the COVID-19 pandemic: a cross- sectional exploratory survey from Dharan, Nepal
}

Kadir Alam ( $\sim$ alamkad2050@gmail.com )

BP Koirala Institute of Health Sciences https://orcid.org/0000-0002-4133-6956

\section{Subish Palaian}

Ajman University

Pathiyil Ravi Shankar

Oceania University of Medicine

Nisha Jha

KIST Medical College

Research article

Keywords: COVID-19, Face masks, General public, Knowledge, attitude and practice, Nepal

Posted Date: July 28th, 2020

DOI: https://doi.org/10.21203/rs.3.rs-42148/v1

License: (c) (i) This work is licensed under a Creative Commons Attribution 4.0 International License.

Read Full License 


\section{Abstract}

Background: Measures to prevent and control coronavirus disease-19 (COVID-19) include regular handwashing, physical distancing and covering mouth and nose using a face mask, thereby reducing spread of droplets. Use of facemask is considered as a cheap, effective and safe method with minimum disruption in day-to-day life. This study assessed the knowledge and practice of Nepalese general public on face mask use during lockdown period of COVID-19 pandemic.

Method: A cross-sectional study using a self-developed, validated questionnaire (Cronbach alpha 0.556) was conducted in Dharan, eastern Nepal during May, 2020. Pharmacists from ten pharmacies, spread throughout Dharan city, after relevant training by the principal investigator, administered and recorded the responses from a selected sample stratified across age, gender, education and place of residence. Completed questionnaires were checked for consistency, coded and entered in IBM SPSS Version 26 and data was tested for normality using one-sample K-S test. Descriptive analyses were performed for demographic parameters and inferential statistics performed for outcome variables calculating median scores among different subgroups which were further compared using appropriate non-parametric tests at alpha $=0.05$.

Results: Altogether 381 individuals, males [211 (55.4\%)] and females [170 (44.6\%)] participated. Ninetythree $(24.5 \%)$ respondents were between $20-30$ years of age and least number $3(0.8 \%)$ were above 70 years; 127 (33.3\%) participants were housewives. Maximum 200 (52.5\%) participants were educated between classes VIII to XII; seven (1.8\%) were having postgraduate education; 129 (33.9\%) participants were hill tribes. Knowledge scores were good (median score 16; maximum score 18). Around $20 \%$ of participant had never used face mask before the pandemic; majority of population (80\%) were aware about the ongoing pandemic. Majority were aware about washing hands (92.6\%) before using mask, covering mouth and nose (78.7\%), and avoiding touching the mask while wearing (42.3\%). Knowledge scores were significantly higher among men $(p=0.038)$, among younger age groups $(p=0.010)$, and among persons with greater education $(p=0.048)$.

Conclusion: The knowledge scores were good and public were aware about proper use of face masks. Educational interventions could be targeted to those with lesser knowledge, and steps to promote sustained face mask use can be beneficial.

\section{Background}

The World Health Organization received information about pneumonia of unknown cause from Chinese authorities in Wuhan, China on December 31, 2019 which was soon shown to be caused by a coronavirus temporarily named 2019-nCoV and later called severe acute respiratory syndrome-coronavirus-2 (SARSCoV-2) [1]. Coronaviruses (CoV) are a large family of viruses causing illness ranging from the common cold to more severe diseases. A novel coronavirus (nCoV) is a new strain that has not been previously identified in humans [2]. Looking at the severity and spread, Coronavirus diseases (COVID-19) has been 
declared as a global pandemic by the World Health Organization (WHO) on 11 March 2020. As per the WHO press release on 27 June 2020 at 8:18 am, globally there have been 9653048 confirmed cases of COVID-19 and 491128 deaths [3]. The first case in Nepal was diagnosed and reported on 25th January 2020 [4] As of 6th July, 2020, total infected, active case and death toll due to COVID 19 in Nepal was 15784, 6547 and 34 respectively [5]. Government of Nepal has increased the provision of isolation beds in the country, locked down the whole country, and sealed international borders including the open border with India [5, 6]

Measures to prevent and control coronavirus disease-19 (COVID-19) include regular handwashing, physical distancing and covering mouth and nose using a face mask, thereby reducing spread of droplets. It is advised to wear masks in public during this pandemic for reducing the risk of infection transmission [7]. The disease is highly contagious and can be transmitted by respiratory droplets [1] which can be released during activities like speaking, coughing and sneezing [8].

Covering of face is one of the major measures recommended for prevention. It prevents the spread of droplets and also help in maintaining respiratory hygiene. Several guidelines suggest the use of face mask reduces infection transmission. A study from Bangladesh suggests that about $72 \%$ of people strongly believed that covering nose and mouth during coughing and sneezing will prevent COVID-19 transmission [9].

Masks are considered as one of the important protective measure for all individuals. Masks can be made of different materials and are of various designs. These different types of masks have different filtering capacities [10]. There are several types of masks like, surgical mask, cotton face mask, N-95 face mask, cloth mask and plastic lined mask. Among these, most effective mask has been the $\mathrm{N}-95$ face mask and is recommended while conducting clinical procedures and for delivering clinical care for COVID-19 patients [11]. There are no studies published from Nepal, hence, the study was planned to assess the knowledge and practice of the Nepalese general public on face mask use during lockdown period of COVID-19 pandemic.

\section{Methods}

\section{Study design}

A cross sectional survey assessing the general public's knowledge and practice regarding face mask use.

\section{Study duration}

The data collection was done during 15th May to 20th June, 2020, when the country was under lockdown due to COVID-19.

\section{Study site}


The study was conducted at Dharan, a city located in the eastern part of Nepal with a population of approximately $1,50,000$, located closed to the border with India. This city was selected since it has a mixture of population in terms of age, gender, ethnicity, educational qualifications etc., who would be available at the time of lockdown as the city hosts a large number of healthcare and educational centers.

\section{Sample selection}

Any individual willing to participate in the study as per the inclusion and exclusion criteria were enrolled. A mixed population with multiple knowledge levels, and from multiple professions covering both genders were enrolled.

\section{Sample size calculation}

The sample size was calculated using Raosoft sample size calculator using the formula below [15]

Sample size $=Z^{2 \star}(p)^{\star}(1-p) / c^{2}$

Where, $\mathrm{c}=$ margin of error, $\mathrm{P}=$ Prevalence of the characteristic

Thus, the sample size (n) at 95\% confidence interval and $5 \%$ margin of error

Calculated sample size was $n=1.96^{2} \times 0.564 \times 0.463 /(0.05) 2=377.86 \sim 378$

The prevalence (p) value was taken from study conducted by Kumar $\mathrm{J}$ et al. in Pakistan [12]

The calculated sample size was 378 and a total of 380 responses were collected

\section{Sampling Technique}

Since Dharan has a mixed population it was difficult to identify a definite population at a definite locality. Ten areas spread uniformly through the city were identified and pharmacist having pharmacy in those localities were contacted to serve as data collection centers. The community pharmacists were trained by the principal investigator (KA) on aspects such as contents of the questionnaire, obtaining participants' consent and responses from the general public while maintaining social distancing, stratification of sample, and entering the responses.

\section{Inclusion and exclusion criteria}

Individuals of both gender who had completed 15 years of age were considered eligible for the study. Any individual visiting the pharmacies with respiratory symptoms or unwilling to respond to the survey were excluded.

Stratification of study sample: The stratification of the total sample of 378 was based on the National demographic data of Nepal- 2019 [13]. The gender distribution was stratified as 0.96 males per 1 female, 
age group $15-40$ yrs. 50\% and above 40 yrs. 50\%; literate (56\%) versus illiterate (44\%): urban $20.2 \%$ rural: $79.8 \%$ However, due to ongoing lockdown strict stratification could not be maintained during the study.

Study questionnaire: The study questionnaire was designed by the researchers based on their understanding and referring to WHO guidelines on face mask use published during the COVID-19 pandemic [14]. The questionnaire had two parts Part I: Demography, Part II: General public knowledge and practice on face mask use and related aspects

\section{Part I: Part I: Demography}

This part collected information on age, gender, educational qualifications, occupation and ethnicity.

\section{Part II: General public knowledge and practice on face mask use and related aspects}

This part had a total of 18 questions; 5 'yes or no' questions, one right or wrong question, two open ended questions on how to dispose face masks and methods other than face mask effective in preventing or reducing the impact of COVID-19, and the last question examining the five steps on correct use of face mask recommended by the WHO [14]. There were also 9 statements scored using a 3-point Likert type questions with responses of agree, neutral and disagree. The final version of the study questionnaire was translated into Nepali following the forward-and-backward process. Thus, the version provided to pharmacists was in Nepali language which was then subjected to pilot testing.

\section{Validity Of The Questionnaire}

The study questionnaire was content validated by the researchers and a public health expert with the questionnaire themes matched with the study objectives. The validity of the questionnaire was noted by pilot testing the questionnaire on ten subjects who were later excluded from analysis in the main study. The reliability was assessed by calculating Cronbach's alpha. The score was 0.56 upon removal of four questions with poor reliability scores and this modified questionnaire was used in the final study.

\section{Method of data collection}

Since the study was conducted during lockdown it was not possible to collect the responses directly from the general public. Hence trained community pharmacy practitioners were contacted to collect the data from their visitors. During the data collection process, personal hygiene and social distancing were maintained and while collecting the responses, both the respondent and the community pharmacists wore face masks. A total of ten pharmacies were identified from various areas of Dharan and the community pharmacists were trained individually by the principal investigator regarding the questionnaire and how to record the responses. The principal investigator oversaw the collection of responses and found the process adequate and appropriate.

\section{Data analysis}


The completed questionnaire was verified by the principal researcher and details entered in IBM SPSS Statistics for Windows, Version 26 and the normality of the data checked using one-sample KolmogorovSmirnov test $(p<0.05)$. The demographic parameters were analyzed descriptively and tabulated as number and percentages. Independent-sample median test was used to compare the scores among different subgroups of respondents, at alpha $=0.05$. Further post hoc analyses were performed for statistically significant pairs using Bonferroni correction for multiple tests at alpha $=0.05$. The number (percentage) of individuals answering each question correctly was noted. The number of individuals who answered all five steps regarding the correct use of a face mask was calculated. The proportion of individuals answering all five steps correctly among different subgroups were compared using chi-square test $(p<0.05)$.

\section{Pilot testing}

A pilot study was conducted to perform the feasibility of the study and to identify any technical difficulties in collecting the data.

\section{Results}

Three hundred and eighty-one individuals participated in the study. Table 1 shows their demographic characteristics. Majority of respondents were below 50 years of age. Males were more at $211(55.4 \%)$ and the highest percentage were housewives and students [127 (33.3\%)]. Most respondents [200 (52.5\%)] had studied till high school (standards VIII to XII). Majority of respondents were from the hill tribes [129 (33.9\%)]. The hill tribes included Rai, Limbu, Kirati, Gurung, Magar, Tamang among others. The Hindu castes (other than Brahmin and Chettri) and Christian were included in 'Others'. 
Table 1

Demographic characteristics of respondents $(n=$ 381)

\begin{tabular}{|ll|}
\hline Characteristic & Number (percentage) \\
\hline Age (in years) & $40(10.5)$ \\
$15-20$ & $89(23.4)$ \\
$20-30$ & $93(24.4)$ \\
$30-40$ & $79(20.7)$ \\
$40-50$ & $53(13.9)$ \\
$50-60$ & $20(5.2)$ \\
$60-70$ & $6(1.6)$ \\
Greater than 70 & \\
\hline Gender & $211(55.4)$ \\
Male & $170(44.6)$ \\
Female & \\
\hline Occupation & $47(12.3)$ \\
Blue collar & $15(3.9)$ \\
Agriculture & $63(16.5)$ \\
White collar & $62(16.3)$ \\
Business & $127(33.3)$ \\
Housewife and student & \\
\hline Education & $9(2.4)$ \\
Illiterate & $15(3.9)$ \\
Primary & $28(7.3)$ \\
Secondary & $200(52.5)$ \\
High school & $42(11.0)$ \\
Graduate & \\
Postgraduate & $1.8)$ \\
Professional & \\
\hline
\end{tabular}




\begin{tabular}{|ll|}
\hline Characteristic & Number (percentage) \\
\hline Ethnicity & $129(33.9)$ \\
Hill tribes & $78(20.5)$ \\
Newar & $58(15.2)$ \\
Brahmin & $57(15.0)$ \\
Chettri & $15(3.9)$ \\
Muslim & $42(11)$ \\
Others & \\
\hline
\end{tabular}

The questionnaire used is shown in Additional file 1. The total score was obtained by adding the scores of statements/questions 1, 2, 3, 4 (with five subsections), 5 and 7 (with nine sub questions). Question 6 dealt with measures other than lockdown which can reduce the spread of the pandemic. Seventy-two respondents (18.9\%) mentioned lockdown, 305 (80.1) mentioned handwashing, 135 (35.5) mentioned sanitization of objects and surroundings, 25 (6.6\%) mentioned avoiding handshake as a form of greeting, 28 (7.3\%) mentioned covering of face before sneezing, while avoiding crows and following social distancing measures were mentioned by $80(21.0 \%)$ and $218(57.2 \%)$ respondents.

The distribution of the individual and the total scores were checked for normality using one-sample Kolmogorov-Smirnov test $(p<0.05)$. The distribution was not normal and hence median and interquartile range were used as measures of central tendency and variation. The median total score was 16 and the interquartile range was 3 . The maximum possible score was 18.

Figure 1 shows the general public's ability to mention the WHO recommended steps for using a face mask correctly. All the individual steps had over $75 \%$ correct response with Step V having $85.04 \%$ responses.

(insert Fig. 1 here)

Table 2 shows the distribution of median scores according to demographic characteristics of the respondents. The scores were significantly higher among younger respondents, and more educated respondents. On doing pair-wise comparisons the scores were significantly higher among respondents between 10 to 20 years of age compared to those between 50 to 60 years $(p=0.042)$ and those between $60-70$ years $(p=0.012)$. With regard to education the scores were significantly lower among illiterate respondents compared to those who had completed secondary school $(p=0.022)$, and among illiterate compared to respondents with professional education $(p=0.012)$. The median score of all individual statements was 1. 
Table 2

Median scores among different subgroups of respondents

\begin{tabular}{|lll|}
\hline Characteristic & Median score & P value \\
\hline Age (in years) & 17 & 0.010 \\
$15-20$ & 16 & \\
$20-30$ & 16 & \\
$30-40$ & 16 & \\
40-50 & 14 & \\
50-60 & 14 & \\
60-70 & 13 & \\
Greater than 70 & & \\
\hline Gender & 16 & \\
Male & 15.5 & \\
Female & & \\
\hline Occupation & 14.5 & \\
Blue collar & 16 & \\
Agriculture & 16 & \\
White collar & 15 & \\
Business & 15 & \\
Housewife and student & & \\
\hline Education & 9 & \\
Illiterate & 14 & \\
Primary & 15.5 & \\
Secondary & 16 & \\
High school & & \\
Graduate & & \\
Postgraduate & & \\
Professional & & \\
\hline
\end{tabular}




\begin{tabular}{|lll|}
\hline Characteristic & Median score & P value \\
\hline Ethnicity & 15 & 0.524 \\
Hill tribes & 15 & \\
Newar & 16 & \\
Brahmin & 16 & \\
Chettri & 16 & \\
Muslim & 15 & \\
Others & & \\
\hline
\end{tabular}

Table 3 mentions the number and percentage of respondents who answered each question yes or correctly. The percentage was over $90 \%$ for most questions. The number of respondents who could mention all five steps of using a face mask properly was 201 (52.8\%). The proportion of respondents who mentioned all five steps correctly was higher among younger respondents (less than 50 years of age) ( $p$ $=0.001)$. The proportion was also higher among those with higher education levels $(p=0.005)$. 
Table 3

Number of individuals answering each question either yes or correctly

\section{Question}

Number

(percentage)

Have you ever used face mask?

Are you aware of the ongoing COVID-19 pandemic?

79 (20.7)

$362(95)$

$365(95.8)$

What is the
another?

Respiratory contact

Should a person who doesn't have any symptoms wear a face mask to

prevent/protect against transmission of COVID-19?

Using a face mask is important to tackle COVID-19

$358(94.0)$

I would like to wear a face mask since it protects me.

$378(99.2)$

All health care workers must use face mask while on duty.

$372(97.6)$

These days the pharmacies have hiked the price of face masks.

$231(60.6)$

In case of absence of a commercial face mask, I would prefer to use a home-made face mask.

$256(67.2)$

I can make a face mask from a simple piece of household cloth.

$173(45.8)$

Though facemask is good it will be better to use it along with social distancing.

$332(87.1)$

Wearing a face mask is going to be necessary approach for the next few months.

$358(94.0)$

After usage face masks should be disposed carefully to prevent virus transmission.

$355(93.2)$

\section{Discussion}

COVID-19 pandemic is a major public health emergency. Lack of effective drug treatments and preventive vaccines has required adoption of different non-pharmacological measures to mitigate the problem to the maximum possible extent. Various strategies such as social distancing, lock downs and use of facemask are considered effective interventions by many health experts and policy makers. Wearing facemask by the public was tried even during previous pandemic like situations such as influenza as a viable strategy to prevent virus transmission through respiratory route [16]. During the COVID-19 pandemic several countries have emphasized wearing face mask by the public and implemented multiple measures to compel people to wear masks [17], to such an extent that some countries are imposing fines for not wearing masks in public [18]. In Nepal, the government recommends use of face mask by the general public in line with the WHO guidelines on face mask use [19]. Face mask reduces the spread of infection through nasal and oral routes and controls the spread of COVID-19 by reducing the amount of infected saliva and respiratory droplets released into the air from individuals with subclinical or mild COVID-19 
symptoms [20]. The SARS-CoV-2 is a large sized virus (approximately $120 \mathrm{~nm}$ in diameter) [21] and can be filtered by face masks. Currently there are no studies in Nepal assessing the general public's knowledge and use of face masks during the ongoing COVID-19 pandemic.

In the current research only one-fifth of the respondents have ever used facemask at the time when COVID-19 was already present in the country for about four months and the country was under lockdown during the time of conducting the research. In a similar study from Malaysia, nearly half of the general public studied wore face masks [22] and in Pakistan $91 \%$ of general public felt wearing facemask should be used as a preventive measure for COVID-19 [23]. In contrast to their practice of wearing face mask, the respondents in the current study showed a very high knowledge as demonstrated by correct response to most questions by over $90 \%$ of study respondents. Thus, as shown in the Malaysian study [22], the present research also documents that knowledge scores are not associated with face mask use behaviors. Such a situation of high knowledge linked to poor facemask use was even observed in a study from Pakistan conducted among health professionals which showed a positive attitude among health professionals, but moderate-to-poor level of knowledge and practice regarding the use of face mask [24].

In the present research the respondents' knowledge scores were significantly lower among the illiterate cohort compared to those who had completed secondary school and those with professional education. This can be definitely attributed to the availability of digital technology, [24, 25], electronic and print resources in spreading awareness to the educated people who are more likely to benefit from these resources. The telecommunication service providers in Nepal have also created awareness messages which are played while dialing any phone numbers in the country, which is a welcome effort, as most of the country now has access to mobile phones [26]. Thus, it is mandatory to explore initiatives such as radio programs [27], street plays [28], art [29] etc., as alternative options which could reach even to illiterate and aged people.

In the present research, the knowledge scores were significantly higher among respondents between 10 to 20 years of age compared to those between 50 to 60 years and those between 60-70 years. Similar to the current study findings, the Malaysian study [22] found wearing of face masks to be associated with gender, age group, region, occupation and income group. In general, younger people are more likely to be aware about the pandemic and its prevention strategy of using facemask. However, poor knowledge among elderly people is worrisome as the elderly are more likely to suffer from COVID-19 complications and associated mortality [30]. Thus, it is mandatory to create age specific awareness programs using media which the elderly are aware of and have access to.

In the current research, only over half of the respondents could correctly mention all the five steps of using a face mask properly. Face masks do not provide protection if they fit improperly and there are gaps between the surface of the mask and face [31] Of the respondents answering all steps correctly, a higher proportion was among younger respondents aged less than 50 years and those with higher education levels. Interventions are needed to demonstrate correct use of face mask which can be 
conducted by distributing pamphlets and information on correct steps to be followed. The WHO has videos demonstrating correct use of face mask which could be used to educate the public [19].

While answering one of the questions on whether face mask can be made from a piece of cloth, more than half of the respondents disagreed, suggesting that public were not aware of home-made masks. Homemade face masks could be potentially beneficial and economic and easily available at all times and can be even reused with adequate care and not be shared among others [32].

This study had a few limitations. Though the study found a high knowledge among respondents and identified the factors influencing the knowledge scores, the source of knowledge among respondents was not assessed. Assessing the knowledge source would have given the researchers an opportunity to recommend more specific interventions. This study also did not evaluate any specific reasons (including myths) for not using facemask by the general public, and finally the study was conducted only in one city in Nepal and hence cannot be generalized to the entire nation. This study also lacks triangulation as the information was collected only by using a questionnaire. In Nepal, currently there are two layered and three-layered face masks and this research focused on face mask as a generic and not on any of the specific types.

\section{Conclusions}

The general public in Dharan, Nepal possessed a high knowledge on facemask use during COVID-19. However, the practice of face mask use was low and influenced by education, literacy and age. Specific interventions targeting elderly and illiterate people using methods other than electronic and printed sources may be beneficial.

\section{List Of Abbreviations}

CoV: Coronaviruses; nCoV: Nobel Coronavirus; WHO: World Health Organization.

\section{Declarations}

Ethical Approval and consent to participate: The research proposal was approved by the Nepal health Research Council, the National health research authority that oversees conduct of human research in the country. (Approval number 2385 dated $12^{\text {th }}$ May, 2020). The participants were informed about the purpose of the research and written consent from participant were obtained prior to enrolling them. In case of age under 15 participants, consent were taken from their parent or legal guardian. Anonymity was maintained throughout the research and no information related to individual respondents are available in public domain.

Consent for publication: We have not used any personal informatirtion or images. So, this is not applicable for this manuscript. 
Availability of data and materials: The datasets used and/or analyzed during the current study are available from the corresponding author on reasonable request.

Competing interests: We don't have any financial and non-financial competing interests.

Funding: No funding was obtained for this study

Authors' contributions: KA and SP conceived and designed the study. PRS and SP finalized the methodology and tools used. KA collected the data. PRS, SP analysed the data. NJ and PRS and SP drafted the manuscript. All the authors made significant contributions to writing the manuscript and reviewing the literature. The order of authorship as placed in the manuscript is final and accepted by the coauthors. The final manuscript has been read and approved by all the authors.

\section{Authors information:}

${ }^{1}$ Department of Pharmacology and Therapeutics, B.P. Koirala Institute of Health Sciences, Dharan, Nepal. Department of Pharmacy, Ajman University, Ajman, UAE. ${ }^{3}$ Department of Basic Medical Sciences, Oceania University of Medicine, Apia, Samoa. ${ }^{4}$ Department of Clinical Pharmacology and Therapeutics, KIST Medical College, Lalitpur.

Acknowledgements: Authors would like to acknowledge the community pharmacists for their help in data collection. We are also thankful to the study respondents who spent their valuable time in responding the survey.

\section{References}

1. World Health Organization. Rolling updates on coronavirus disease (COVID-19). https://www.who.int/emergencies/diseases/novel-coronavirus-2019/events-as-they-happen (2020). Accessed 27 Jun 2020.

2. National Institute of Allergy and Infectious Disease. Overview of Coronavirus. https://www.niaid.nih.gov/diseases-conditions/coronaviruses (2020). Accessed 27 Jun 2020.

3. World Health Organization. COVID-19 Dashboard. https://covid19. who.int/ (2020). Accessed 27 Jun 2020.

4. Bastola A, Sah R, Rodriguez-Morales AJ. The first 2019 novel coronavirus case in Nepal. Lancet Infect Dis. 2020;20:279-80.

5. Ministry of health and population, Government of Nepal. Coronavirus disease (COVID-19) outbreak updates \& resource materials. (2020). https://heoc.mohp.gov.np/update-on-novel-corona-virus-covid19. Accessed 27 Jun 2020.

6. Shrestha R, Shrestha S, Khanal P, Bhuvan KC. Nepal's First Case of COVID-19 and public health response. J Travel Med. 2020. doi:10.1093/jtm/taaa024. 
7. Feng S, Shen C, Xia N, Song W, Fan M, Cowling BJ. Rational use of face masks in the COVID-19 pandemic. Lancet Respir Med. 2020;8:434-6.

8. Morawska L. Size distribution and sites of origin of droplets expelled from the human respiratory tract during expiratory activities. J Aerosol Sci. 2009;40:256-69.

9. Farhana K. Knowledge and perception towards Novel Coronavirus (COVID 19) in Bangladesh. Int Res J Bus Soc Sci 6:76-9. https://doi.org/10.2139/ssrn.3578477.

10. Brosseau L, Ann RB. N95 respirators and surgical masks. Centers for Disease Control and Prevention. https://blogs.cdc.gov/niosh-science-blog/2009/10/14/n95/. Accessed 20 Jun 2020.

11. Leung NHL, Chu DKW, Shiu EYC, et al. Respiratory virus shedding in exhaled breath and efficacy of face masks. Nat Med. 2020;26:676-80. https://doi.org/10.1038/s41591-020-0843-2.

12. Kumar J, Katto MS, Siddiqui AA, Sahito B, Jamil M, Rasheed N, et al. Knowledge, Attitude, and Practices of Healthcare Workers Regarding the Use of Face Mask to Limit the Spread of the New Coronavirus Disease (COVID-19). Cureus. 2020. doi 10.7759/cureus.7737.

13. Central Bureau Of Statistics, Government of Nepal. (2018). District Profile of Sunsari 2074. https://cbs.gov.np/sunsari/. Accessed 5 Apr 2020.

14. World Health Organization. How to wear a non-medical fabric mask safely. (2020). https://www.who.int/emergencies/diseases/novel-coronavirus-2019/advice-for-public/when-andhow-to-use-masks. Accessed 17th April 2020.

15. Israel GD. Determining Sample S. (1992), Revised 2009. http://edis.ifas.ufl.edu Accessed 23 Apr 2020.

16. Brienen NCJ, Timen A, Wallinga J, van Steenbergen JE, Teunis PF. The effect of mask use on the spread of influenza during a pandemic. Risk Anal. 2010;30:1210-8.

17. Which countries have made wearing face masks compulsory? Al Jazeera News. https://www.aljazeera.com/news/2020/04/countries-wearing-face-masks-compulsory200423094510867.html. Accessed 3 Jul 2020.

18. Still Confused About Masks? Here's the Science Behind How Face Masks Prevent Coronavirus Bai N. Still Confused About Masks? Here's the Science Behind How Face Masks Prevent Coronavirus (2020). https://www.ucsf.edu/news/2020/06/417906/still-confused-about-masks-heres-sciencebehind-how-face-masks-prevent. Accessed 3 Jul 2020.

19. World Health Organization. Coronavirus disease (COVID-19) advice for the public: When and how to use masks. https://www.who.int/emergencies/diseases/novel-coronavirus-2019/advice-forpublic/when-and-how-to-use-masks. Accessed 5 Jul 2020.

20. Cheng VC, Wong SC, Chuang VW, et al. The role of community-wide wearing of face mask for control of coronavirus disease 2019 (COVID-19) epidemic due to SARS-CoV-2. J Infect. 2020. doi:10.1016/j.jinf.2020.04.024.

21. New Coronavirus (SARS-CoV-2) and the Safety Margins of Plasma Protein Therapies. Plasma Protein Therapeutics Association. (2020). https://www.pptaglobal.org/media-and-information/ppta- 
statements/1055-2019-novel-coronavirus-2019-ncov-and-plasma-protein-therapies. Accessed $5 \mathrm{Jul}$ 2020.

22. Azlan AA, Hamzah MR, Sern TJ, Ayub SH, Mohamad E. Public knowledge, attitudes and practices towards COVID-19: A cross-sectional study in Malaysia. PLoS ONE. 2020. doi.org/10.1371/journal.pone.0233668.

23. COVID-19 AND ITS PREVENTIVE MEASURES, IN PUBLIC OF PAKISTAN Mirza T, Ali R, Khan H. THE KNOWLEDGE AND PERCEPTION OF. COVID-19 AND ITS PREVENTIVE MEASURES, IN PUBLIC OF PAKISTAN. PAFMJ [Internet]. 30Apr.2020 [cited 20Jul.2020];70(2):338-5. Available from: https://www.pafmj.org/index.php/PAFMJ/article/view/4186.

24. Ting DS, Carin L, Dzau V, Wong TY. Digital technology and COVID-19. Nature Med. 2020;26:459-61.

25. Chan AKM, Nickson CP, Rudolph JW, Lee A, Joynt GM. Social media for rapid knowledge dissemination: early experience from the COVID-19 pandemic [published online ahead of print, 2020 Mar 30]. Anaesthesia 2020;10.1111/anae.15057.

26. Rise in number of mobile phone users. (2016). https://www.ktm2day.com/2016/01/29/rise-innumber-of-mobile-phone-users/ Accessed 2 Jul 2020.

27. United Nations. UN radio spreads Covid-19 information to remote areas. https://www.un.org/en/uncoronavirus-communications-team/un-radio-broadcasts-spread-covid-19-information-remote-areas. Accessed 5 Jul 2020.

28. Press Trust of India. Tribal women perform street play on Covid-19 to spread awareness among tea garden workers. https://www.hindustantimes.com/it-s-viral/tribal-women-perform-street-play-oncovid-19-to-spread-awareness-among-tea-garden-workers/story-8AIQBVP0Kn17iUEYmR7eyO.html. Accessed $5 \mathrm{Jul} 2020$.

29. Magdalene Mukami. Somali artists use art to spread COVID-19 awareness. Artists in Horn of Africa country fight misinformation, rumors and stigma surrounding coronavirus pandemic. Anadolu Agency. (2020). https://www.aa.com.tr/en/africa/somali-artists-use-art-to-spread-covid-19awareness/1890554. Accessed 5 Jul 2020.

30. Liu K, Chen Y, Lin R, Han K. Clinical features of COVID-19 in elderly patients: a comparison with young and middle-aged patients. J Infect. 2020. doi:10.1016/j.jinf.2020.03.005.

31. Food US, Administration D. Respirators N, Masks S, Masks F. (2020). https://www.fda.gov/medicaldevices/personal-protective-equipment-infection-control/n95-respirators-surgical-masks-and-facemasks. Accessed 5 Jul 2020.

32. Center for disease control and prevention. Use of Cloth Face Coverings to Help Slow the Spread of COVID-19. (2020). https://www.cdc.gov/coronavirus/2019-ncov/prevent-getting-sick/diy-cloth-facecoverings.html. Accessed 5 Jul 2020.

\section{Figures}




\section{Number of respondents mentioning each step correctly $(n=381)$}

330

320

310

300

290

280

270

260

250
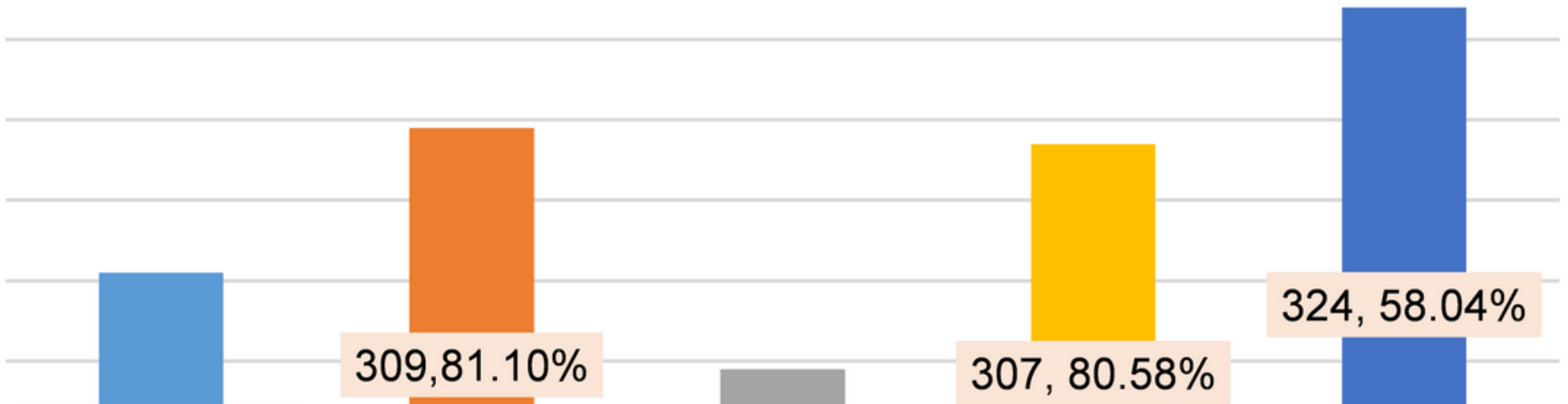

$324,58.04 \%$

$-291,76.38 \%$

Figure 1

General public's knowledge on WHO recommended face mask use steps Step I: Before putting on a mask, clean hands with alcohol-based hand rub or soap and water; Step II: Cover mouth and nose with mask and make sure there are no gaps between your face and the mask; Step III: Avoid touching the mask while using it; if you do, clean your hands with alcohol-based hand rub or soap and water; Step IV: Replace the mask with a new one as soon as it is damp and do not re-use single-use masks; Step V: To remove the mask: remove it from behind (do not touch the front of mask); discard immediately in a closed bin; clean hands with alcohol-based hand rub or soap and water, adopted from Reference 14 .

\section{Supplementary Files}

This is a list of supplementary files associated with this preprint. Click to download.

- Questionnaire.docx 